\title{
INTERACÃO DAS FRONTEIRAS E O PONTO DE VISTA EINOGRÁFICO: DINÂMICAS MIGRATÓRIAS RECENTES EM GOVERNADOR VALADARES ${ }^{*}$
}

\author{
Igor José de Renó Machado \\ Universidade Federal de São Carlos - Brasil
}

Resumo: Este artigo trata do complexo tema das fronteiras, ancorado numa perspectiva etnográfica. A fronteira é vista a partir de sua relevância entre os valadarenses, habitantes da cidade brasileira de Governador Valadares (MG), o mais conhecido centro de emigração internacional no Brasil. O trabalho é estruturado em duas partes, a primeira demonstra a relação entre os fluxos migratórios valadarenses e diversas fronteiras geopolíticas que os sujeitos migrantes enfrentam; a segunda descreve uma dinâmica cultural característica das camadas pobres em Valadares, a construção de Casas em sentido lévi-straussiano. A relação entre os dois processos é que o segundo, a divisão infindável dos núcleos familiares, impulsiona a intensidade do primeiro, o cruzamento das fronteiras geopolíticas.

Palavras-chave: família, fronteiras, Governador Valadares, imigração internacional.

Abstract: Based upon an ethnographical perspective, this paper deals with the complex subject of borders. The border is seen from the viewpoint of its relevance for the Valadarenses, citizens of Governor Valadares, a town in Minas Gerais known as a center of international emigration in Brazil. The paper is divided in two parts; the first part examines the relation between the Governor Valadares migratory flows and

\footnotetext{
* Agradeço ao CNPq, à Fapesp e ao convênio Capes-Grices (para o projeto Circulação Transnacional, Fronteiras e Identidades) pelos financiamentos que possibilitaram a realização dessa pesquisa. Agradeço os comentários de Bela Feldman-Bianco, Ruben George Oliven, Cristiana Bastos, Ramón Sarro, Carmem Rial, Denise Jardim, Douglas Mansur, Cristina Maher, Guilherme Dias, Liliana Sanjurjo, Paulo Muller e Rafael Evangelista no contexto de uma oficina de trabalho no Cemi/Unicamp e aos pareceristas anônimos da revista Horizontes Antropológicos. Agradeço especialmente a Ellem Reis, Alexandra Almeida, Fábio Stabelini e Amanda Guerreiro.
} 
diverse geopolitical borders faced by these migrants; and the second part describes a cultural dynamic among the poor population of Valadares, the construction of Houses (in Lévi-Straussian sense). The relation between the two processes indicates that the intense division of the familiar nuclei stimulates the intensity of the crossing of the geopolitical borders.

Keywords: borders, family, Governor Valadares, international emigration.

\section{Introduç̃o}

Este artigo pretende expor uma reflexão sobre o complexo tema das fronteiras, ancorado numa perspectiva etnográfica. Aqui interessa a fronteira a partir de sua relevância entre os valadarenses, ${ }^{1}$ habitantes da cidade brasileira de Governador Valadares (MG), o mais conhecido centro de emigração internacional no Brasil. Buscarei não apenas elencar fronteiras que atravessam a experiência de valadarenses, mas estabelecer relações entre elas, uma vez que a etnografia desenvolvida na cidade indica que alguns processos apresentam afinidades com outros, não sendo possível, portanto, apenas descrever fronteiras. É necessário explicá-las em relação aos processos culturais produzidos em Valadares. ${ }^{2}$

Para atingir tais objetivos, o trabalho é estruturado em duas partes aparentemente distintas, que correspondem a descrições etnográficas de duas ordens de fronteiras. A primeira parte demonstra a relação entre os fluxos migratórios valadarenses e diversas fronteiras geopolíticas que os sujeitos migrantes enfrentam: no caso, a fronteira México-EUA, os vistos para entrada no México

\footnotetext{
Sigo aqui a perspectiva de Viveiros de Castro (1999).

2 A pesquisa foi realizada em Governador Valadares em cinco momentos: o primeiro realizado em julho de 2005, por Ellem Saraiva Reis e Lara Rezende; o segundo realizado em fevereiro de 2006, por Ellem Saraiva Reis e Alexandra Gomes de Almeida; o terceiro realizado em fevereiro de 2007, por Thaísa Yamauie e Arielle Basinello; o quarto, em julho de 2007, por Alexandra Gomes de Almeida e Thaísa Yamauie; e o quinto, em janeiro e fevereiro de 2008, por Fábio Stabelini, Amanda Guerreiro e Alexandra Gomes de Almeida. Essas cinco visitas ao campo resultaram em 11 diários de campo e cerca de 70 entrevistas semiestruturadas. Os entrevistados são, em geral, moradores de bairros pobres da cidade, marcados pela grande emigração internacional. Essas visitas também resultaram em seis relatórios finais de iniciação científica, muito importantes para a sistematização dos argumentos aqui defendidos; são eles: Reis (2006, 2007), Almeida (2006, 2007), Stabelini (2008) e Guerreiro (2008). Os argumentos deste texto se baseiam nas entrevistas e, principalmente, nos diários de campo.
}

Horizontes Antropológicos, Porto Alegre, ano 15, n. 31, p. 167-187, jan./jun. 2009 
e a fronteira europeia. Estabeleço uma ordem entre essas diversas fronteiras, construindo uma espécie de hierarquia de preferências "nativas" entre os candidatos a imigrantes valadarenses.

Em seguida, passo para a descrição de uma dinâmica cultural característica das camadas pobres em Valadares (e também de outras várias regiões brasileiras e portuguesas, ver, por exemplo, Durham, 1978) que aparentemente não se relaciona com a descrição da hierarquia de preferências em relação às fronteiras geopolíticas apresentada anteriormente. ${ }^{3}$ Porém, com o desenvolvimento do argumento ficará claro que o processo cultural, nomeadamente a construção de Casas em sentido lévi-straussiano ${ }^{4}$ entre a população pobre da cidade, permite entender a importância da emigração como uma espécie de atalho para se atingir esse objetivo. A relação entre os dois "processos fronteiriços” é que o segundo, a divisão infindável dos núcleos familiares, impulsiona a intensidade do primeiro, o cruzamento das fronteiras geopolíticas. Há, portanto, uma correlação entre os dois processos: a construção de fronteiras entre núcleos familiares impulsiona a emigração internacional.

Obviamente, a construção das Casas não explica a imigração em Valadares de forma absoluta, já que uma série de outros fatores concorre para a promoção de uma sociedade de migração (conferir, entre outros, Assis, 1999; Fusco, 2001; Siqueira, 2007; Soares, 1999), mas entendo que é um ingrediente sem o qual a dimensão do fenômeno não teria chegado ao que vemos hoje em dia. A importância da descrição dos dois "processos fronteiriços", um de cruzamento de fronteiras geopolíticas e outro de construção de fronteiras entre núcleos familiares é objeto da discussão na parte final do artigo. Busco defender a importância da descrição etnográfica de situações de fronteira, fugindo à oposição colocada recentemente entre os usos da ideia de fronteira pelos border studies e os estudos culturais, que discutirei ao final do artigo.

3 Originalmente, a emigração internacional valadarense era de classe média (Assis, 1999), mas o perfil vem mudando, ao longo da última década, para uma emigração de classe média baixa e classes desfavorecidas, como atesta o trabalho de Siqueira $(2006,2007)$. Essa pesquisa não se utilizou de surveys para compor um quadro socioeconômico dos entrevistados, mas foi integralmente realizada em bairros carentes da cidade.

4 Na referida parte explicarei exatamente como entendo a ideia de Casa em Valadares. Note-se que quando a grafia utilizar a letra maiúscula e o itálico, estarei me referindo ao conceito e ao processo que ele descreve. 
O argumento é que a descrição etnográfica permite uma reflexão que estabelece relações de afinidade entre processos culturais; que o entendimento dessas conexões permite entender mais claramente os fenômenos; que o valor da ideia de fronteira não precisa ser relacionado nem aos exageros dos estudos culturais nem à necessidade de estudos em sociedades fronteiriças, como pretendem afirmar os defensores dos border studies; e, por fim, que uma visão a partir de "dentro" do grupo abre horizontes inesperados para o entendimento desses fenômenos. Assim, este artigo tenta trazer para o foco as unidades analíticas nativas como explicativas do processo migratório, pretendendo entender o que eles consideram como suas fronteiras mais relevantes.

\section{Fronteiras geopolíticas e os impactos nos projetos migratórios valadarenses ${ }^{5}$}

Nesta parte pretendo demonstrar a relevância que as dinâmicas envolvendo a fronteira México-EUA têm para os habitantes de Governador Valadares e as decisões de migração naquela cidade. As decisões políticas de controle de fronteira nos EUA e as decisões sobre a necessidade de emissão de visto pelo México, por exemplo, são fundamentais na configuração dos processos migratórios em Valadares. Essas fronteiras, portanto, constrangem a mobilidade dos valadarenses e têm implicações que veremos a seguir. Para isso, é necessário construir um rápido panorama da história da migração em Valadares.

\section{Histórico}

A história da cidade de Governador Valadares está intrinsecamente ligada ao fluxo emigratório internacional. Desde o último quartel do século passado tornou-se uma espécie de capital nacional da emigração. Como indicam vários autores (Assis, 1999; Sales, 1999; Soares, 1999), essa movimentação era destinada principalmente para os EUA. A emigração de valadarenses para os Estados Unidos ocorreu mais intensamente ao longo das últimas três décadas, devido ao grande fluxo migratório, restrições à entrada e permanência em solo estadunidense por meio da negação de vistos de forma mais

5 Essa parte é um resumo do argumento apresentado em Machado e Reis (2007).

Horizontes Antropológicos, Porto Alegre, ano 15, n. 31, p. 167-187, jan./jun. 2009 
abrangente. Assim, dada essa demanda e a dificuldade de emigração para os Estados Unidos, houve a formação, na cidade, de estruturas e que auxiliariam a entrada na tão sonhada "América” e que usariam de meios ilícitos para a inserção dessas pessoas na sociedade norte-americana. A partir de outubro de 2005 o governo mexicano reintroduziu a necessidade de visto para a entrada de brasileiros no país e, dessa forma, houve, novamente, uma modificação nas formas de atuação dos agenciadores da emigração. Uma das consequências dessa medida foi o aumento do custo e dos perigos para a aventura da migração não-documentada, ${ }^{6}$ aumentando a busca por novos destinos, dos quais Portugal é o mais importante.

Os agenciadores da emigração constroem estruturas que envolvem, além de sistemas de empréstimos, como o esquema ilícito de agiotagem, segmentos de serviços que apresentam regularidade perante a lei brasileira, como no caso das agências de viagens, que auxiliam a entrada do imigrante no país de destino. Através das dicas de comportamento, das formulações de novas rotas de entrada dos valadarenses em Portugal e das reservas fictícias em hotéis portugueses, as agências de viagens contribuem para a efetivação dos projetos migratórios e aproveitam dessas demandas para extrair seu lucro.

Evidentemente, o fluxo de pessoas não se cria apenas com a intenção de elaborar novas rotas de migração (essas, no caso, menos lucrativas), mas também a partir da própria estruturação gradual de redes migratórias que se direcionam também a Portugal, processo que vem se complexificando desde o começo do século. O mesmo processo por qual passou a migração para os EUA acontece agora com Portugal, só que intensificado pela existência prévia das estruturas ilegais de migração. Assim, muito rapidamente, em questão de dez anos, estruturaram-se redes familiares de migração para Portugal, que estimulam ainda mais a movimentação de pessoas para esse país.

Na pesquisa realizada encontramos um grande número de famílias com parentes nos EUA e em Portugal. ${ }^{7}$ A grande maioria dos entrevistados, além de

6 Como também há dificuldades para os valadarenses conseguirem o visto para entrada em território mexicano, as opções são a entrada pela Guatemala, seguida de entrada clandestina no México e viagem clandestina até a fronteira com os EUA ou a falsificação de documentos para conseguir o visto mexicano.

7 Um dos trabalhos de iniciação científica desenvolvidos (Reis, 2006) elaborou uma cuidadosa genealogia de 23 famílias valadarenses, e a maioria delas (cerca de 60\%) possuía membros nos EUA e em Portugal. 
parentes em Portugal, tinha também parentes nos EUA. Assim, ficou evidente que as redes de migração estão se complexificando e se estendendo por mais de um país, oferecendo alternativas diferenciadas para os migrantes. Quando uma pessoa decide emigrar para outro país, ela geralmente tem condições de "optar" entre os EUA e Portugal, e cada vez mais tem a opção de emigrar para outros países (como Inglaterra, por exemplo). Ela poderá contar, se não com algum suporte familiar, ao menos com o suporte de conhecidos em cada um desses países.

\section{Fronteiras e suas consequências}

Geralmente, as pessoas que não possuem condições financeiras para migrar para os Estados Unidos procuram outros destinos. Confirmando essa informação, segundo estimativa do então delegado da Polícia Federal Rui Antônio da Silva, a porcentagem do fluxo migratório valadarense para o exterior está dividida em 50\% para os EUA, 40\% para Portugal e 10\% para outros países. ${ }^{8}$ Os custos de uma migração para Portugal são muito menores, correspondendo apenas ao valor das passagens e o pagamento adiantado de diárias em algum hotel, mais o valor que as pessoas precisam ter em mão para comprovar a capacidade de "passarem por turistas”. Portugal consolidou-se, portanto, como uma alternativa mais barata de migração.

Mas nem por isso as pessoas desejam primeiramente ir para Portugal: muitas não conseguem o valor necessário para uma viagem aos EUA e acabam escolhendo o país. É importante ressaltar que alguns relatos salientaram que muitos valadarenses migraram para solo lusitano com o intuito de conseguir dinheiro para irem para a “América” e outros, para terem registro de viagens no passaporte com o objetivo de facilitar a aquisição do visto no consulado norte-americano. Esses artifícios refletem a consciência da população frente às dificuldades de retirada do visto para os Estados Unidos, o que muitos moradores enfatizam como preconceito contra os valadarenses.

Portugal é um destino que não está vinculado a nenhuma construção histórico-social da cidade ou enraizado no universo simbólico dos valadarenses, como no caso dos Estados Unidos, mas que se tornou atrativo por estar mais

8 Informação dada em entrevista realizada em julho de 2006.

Horizontes Antropológicos, Porto Alegre, ano 15, n. 31, p. 167-187, jan./jun. 2009 
acessível econômica e fisicamente aos emigrantes. Apesar de alguns autores indicarem que o fluxo para Portugal se intensificou a partir de 2001 devido à concessão de autorizações de permanência aos imigrantes com contrato de trabalho, as “APs” (Peixoto; Figueiredo, 2006), percebemos que o estímulo à migração de muitos valadarenses para solo lusitano estava também relacionado ao menor custo da viagem e aos menores riscos de morte, como os que existem na travessia ilegal da fronteira entre México e Estados Unidos. A passagem para os EUA pela fronteira mexicana significa uma aventura perigosa: risco de morte, estupro, de prisão em solo mexicano ou americano. A última opção significa um longo período de prisão em presídios normais, lado a lado com criminosos comuns, esperando pela deportação (se for o primeiro caso de migração ilegal, se for um migrante reincidente, ele pode ficar preso e não ter direito à deportação).

As histórias de tragédias são constantes e correm entre os valadarenses, ativando uma espécie de medo coletivo. A viagem a Portugal oferece-se como possibilidade segura, com nenhum risco à vida e menores riscos financeiros. Como se investe menos dinheiro, o trauma de uma deportação é menor. Este, na verdade, é o único risco: ser deportado e ter a entrada em toda a Europa dificultada.

Assim, vimos que o destino da migração tem se diversificado e Portugal aparece com a segunda opção. Como analisado por Machado (2005), a migração de valadarenses para Portugal é um fenômeno recente e relativamente crescente. Assim, se Valadares não é uma "sociedade de fronteira”, afinal se localiza num estado brasileiro que não faz divisa com nenhum país e não tem costa marítima, as implicações dos processos políticos e policiais de controle de entrada e hierarquização de populações coordenados pelos EstadosNação que estão nos caminhos migratórios dos valadarenses são sentidas como se Valadares fosse efetivamente uma zona de fronteira. As condições de mobilidade (Heyman; Cunninghan, 2004) dos valadarenses têm sido dificultadas no que tange à entrada nos EUA, implicando uma diversificação das movimentações. ${ }^{9}$

9 Pesquisa de campo que está sendo realizada em Valadares enquanto escrevo este artigo, pelos orientandos Fábio Stabelini, Amanda Guerreiro, Roberta Mazer e Flora Guimarães, entretanto, têm identificado uma movimentação mais intensa de retorno, por conta da crise econômica mundial que eclodiu em finais de 2008.

Horizontes Antropológicos, Porto Alegre, ano 15, n. 31, p. 167-187, jan./jun. 2009 
Interessa aqui perceber que as decisões de migrar para os novos destinos são reguladas pelo que acontece no México e EUA e suas implicações e relações com o tradicional fluxo de trabalhadores para os EUA. Ou seja, para valadarenses, a fronteira México-EUA é próxima, cotidiana e presente. O que ali acontece tem consequências diretas nos planos de muitas famílias, caracterizando uma situação de fronteira relevante, determinando nas contas de candidatos a emigrantes e suas famílias a direção a ser tomada. Fronteiras geopolíticas distantes e as respectivas políticas de restrição à mobilidade humana por parte daqueles Estados têm implicações diretas na vida de valadarenses. Essa situação de fronteira e seus constrangimentos macroestruturais é caracterizada por diversos níveis entre fronteiras: as várias fronteiras físicas a serem atravessadas e suas distintas restrições, as fronteiras políticas impostas por esses Estados diversos no que tange à restrição da movimentação, a fronteira financeira para os sujeitos que pretendem enfrentar o projeto migratório e fronteiras simbólicas que tornam alguns destinos mais desejados que outros.

\section{Fronteiras simbólicas: a família e o desejo de migrar ${ }^{10}$}

Nesta parte analiso um processo cultural que tem relação íntima com a migração, no caso, a construção de Casas. Verifica-se que as pessoas migram para construir o projeto futuro de suas famílias e constituir novas centralidades nas suas relações; estando longe, o que produz a relação (o próprio parentesco) não é mais a convivência e o sangue, mas o envio de sinais diacríticos de presença e interesse no núcleo familiar (remessas, bens, telefonemas, e-mails, vídeos). Esse mecanismo configura-se na principal fronteira a ser analisada, aquela que impulsiona a migração e a sustenta, ou seja, a fronteira que se deseja criar como um novo núcleo familiar. As decisões de migrar, influenciadas pelas fronteiras geopolíticas que vimos na primeira parte deste artigo, têm relações profundas com os processos de fissão e fusão de núcleos familia-

10 Esta parte é um resumo do argumento apresentado em Machado (2006). As principais ideias são resumidas e o detalhamento dos dados foi deixado de lado, em prol da evolução da comparação entre os fenômenos “fronteiriços" que analiso. Ao leitor interessado nos meandros do processo que descrevo, remeto ao texto original, que atualmente foi retrabalhado e se encontra em fase de revisão para publicação em outra revista.

Horizontes Antropológicos, Porto Alegre, ano 15, n. 31, p. 167-187, jan./jun. 2009 
res, com sua constante movimentação de fronteiras entre pessoas de mesmas famílias. Vejamos como funciona esse processo.

\section{Casa}

Autores como Carsten (2004) têm re-elaborado a ideia de "sociedades de Casa” de Lévi-Strauss (1986, 1999), usada como instrumento para renovar os estudos sobre parentesco. Carsten não se interessa tanto pela ideia da Casa como uma pessoa moral, ou seja, uma entidade metafísica que perdura para além da vida dos seus membros, mas sobre a Casa como um universo de construção de relações fundamentais da vida de pessoas no mundo inteiro. Influenciada por Strathern, que enfatiza como sujeitos são frutos de relações que constroem e desconstroem ao longo da vida, Carsten analisa as relações que se constroem no interior da casa, preocupada principalmente com a noção complexa de substância. A comensalidade produz a cossubstancialidade em algumas sociedades e esta produz relações variadas (desde proibições de incesto até regras de etiqueta).

Ao re-elaborar uma análise sobre a Casa, Carsten (2004) recorre a noções como corpo, pessoa, gênero, substância e parentesco. Analisar essas dimensões na Casa é observar outras "relações de parentesco", que não são consanguíneas segundo concepções ocidentais, mas são construídas através da moradia em comum. Habitar com outros insere os sujeitos em sistemas de trocas que relacionam e/ou criam parentes. Para a autora, adotar essa perspectiva sobre a Casa permite escapar às formas para lidar com substâncias, permitindo uma postura processual:

I suggest that the very qualitative density of experiences in the houses we inhabit leads many people around the world, including the Malays with whom I lived on the island of Langkawi, to assert that kinship is made in houses through the intimate sharing of space, food, and nurturance that goes on within domestic space. And because being 'made' is usually opposed to being 'given', houses are good places to start examining that theme. (Carsten, 2004, p. 35).

Assim, podemos perceber, em diferentes contextos etnográficos, o modo como o parentesco é "feito" em oposição a um parentesco “dado". A Casa aparece como a produtora do parentesco, visto como conjunto de relações, 
livres do "império do código" versus o “império da natureza”, na concepção de Schneider (1968). ${ }^{11}$

\section{Os projetos futuros da família e a questão dos seus limites e fronteiras em Valadares}

Passemos agora à analise da necessidade imperiosa da compra da casa própria entre as famílias transnacionais de Governador Valadares. Tentarei demonstrar, através do relato recorrente, como essa casa própria é mais que um espaço físico, mas também um lugar de centralidade das relações de um casal. A casa própria é um demarcador da possibilidade de construção da Casa.

A importância da Casa é manifesta nas situações mais variadas da migração. E se poderia aqui elencar várias situações que indicam essa relevância: como a de alguém que fez dívidas com um agiota para pagar a casa própria, mas que não conseguiu arcar com as prestações e se aventurou a migrar para Portugal. Muitos migram explicitamente para comprar uma casa. Outros marcam a data de retorno tendo em vista a quantidade de dinheiro acumulado para comprá-la. Estas citações dão uma ideia da relevância da casa no projeto migratório:

A gente tem claro esse plano de a gente construir para gente a nossa casa própria, ter nosso canto. (Edmar).

Vai terminar de fazer uma construção aqui, está terminando, terminando já vem embora, já tem onde entrar, graças a Deus. (Gabriela).

É o objetivo de toda pessoa que vai para fora, para outro país, é mudar de vida. Construir alguma coisa. Entendeu? Porque, aqui, realmente é difícil. (Cristina).

${ }^{11}$ Essa reconstrução do parentesco a partir da noção de relatedness (traduzida por Fonseca [2007] como “conectividades”) tem uma dívida assumida com a discussão sobre a Casa numa perspectiva mediterrânea. Para uma revisão dessa discussão, ver Pina-Cabral (1991). Para um interessante uso dessa perspectiva, ver Matos Viegas (2007). Aqui, permaneço mais próximo à perspectiva mais sociológica de Lévi-Strauss, em função dos objetivos do texto. Embora leve em consideração a perspectiva de Casa como "lugar do vivido", estou mais interessado na Casa como um modelo de estruturação das relações sociais.

Horizontes Antropológicos, Porto Alegre, ano 15, n. 31, p. 167-187, jan./jun. 2009 
Primeiro porque a vida aqui é muito difícil. Então, quem tem alguma coisa, tem aqui. Quem não tem, não tem nada. Então, eles vão em busca de seus sonhos que é: conseguir uma casa para sua família, comprar um carro para sobreviver. Se eles não conseguem fazer isso, eles vão viver eternamente trabalhando diaa-dia. Então, vai ficar trabalhando dia-a-dia eternamente. O sonho de todos os mineiros é ter uma casa própria para ter um lar para sua família. (Wallace). ${ }^{12}$

O caso nos bairros pobres de Valadares, de onde saem os emigrantes da nossa pesquisa, indica uma vontade coletiva de construção física de uma casa, que seria a sede oficial da própria família. Esse processo demonstra que é a posse da casa que possibilita independência em relação às famílias originais, seja do marido ou da esposa. ${ }^{13}$ Assim, o processo implica a composição de novas Casas e resulta em sucessivos rompimentos, pois não há a vontade de “continuar” os núcleos familiares originais. Na verdade, se constrói uma Casa contra os núcleos familiares originais. Cada Casa dura, portanto, apenas a vida do casal. Morar numa habitação no terreno dos pais é ainda participar da Casa dos pais, subordinadamente. Não temos aqui exatamente a noção de Casa de Lévi-Strauss, que pressupõe alguma, mesmo que mínima, continuidade, mas é, efetivamente, uma casa “à Lévi-Strauss”, pela sua centralidade na organização da estrutura social local, por sua relevância na organização do parentesco e da posse territorial e, claro, por dar impulso à migração internacional, como um atalho rápido para a centralidade. Essa ideia da Casa valadarense (das camadas pobres da população) é uma espécie de Casa relacional, ligada a cada casal como centro de si mesmo, sem perpetuação da família. ${ }^{14}$

Aqui, portanto, convém distinguir a casa (habitação) da Casa (centralidade de relações do casal), pois a segunda ampara a estrutura social e induz à movimentação internacional, apontando para a formação das fronteiras internas à vida local. A primeira é uma necessidade para a existência da segunda, com a condição de ser descolada da casa (habitação) dos pais. Os emigrantes partem para construir Casas e, para isso, precisam de recursos

\footnotetext{
12 Os nomes são fictícios.

13 Siqueira (2006), em sua amostra de emigrantes valadarenses nos EUA, indica que entre os que compraram bens no Brasil, 38\% compraram uma casa urbana, 24\% propriedades rurais e $11 \%$ lotes. Somandose os três números como indicadores de uma vontade de aquisição de futuros lugares de moradia, temos $73 \%$.

${ }^{14}$ Para outra análise sobre o valor da Casa no contexto migratório, ver Feldman-Bianco (1996).
} 
para construir uma casa (habitação) que dê condições e sustentabilidade para aquelas. Também devemos matizar esse descolamento da Casa dos pais, já que não se trata, necessariamente, de pais biológicos: a Casa com a qual se “rompe” para formar a própria pode ser capitaneada por pais, tios e até nãoparentes. Rompe-se com a Casa na qual se inseria anteriormente. Em alguns casos de desamparo social, nem é preciso romper: não se estava relacionado a nenhuma Casa e a migração é uma tentativa de superar esse dilema com uma nova Casa. Como lembra Lévi-Strauss (1986, p. 194), “as casas também [...] nascem e se extinguem [...]” e, em Valadares, esse processo não chega a durar nem uma geração, tamanha a dissolução promovida pelo "atalho" da migração.

Uma situação comum é aquela onde o candidato a migrante mora com seu núcleo familiar numa casa de seus pais, mas ainda assim busca a própria Casa através da aventura da migração. Esse exemplo demonstra como a importância da Casa é muito maior do que seu espaço e segurança: é uma questão de autonomia em relação a outrem, às relações de outrem. Recorrentemente nas entrevistas percebemos a mesma situação de pessoas relativamente bem instaladas em casas dos próprios pais ou sogros, no terreno da Casa destes, mas que não se sentiam donos de uma Casa. Estar no terreno da Casa dos pais significa também estar, de certa forma, preso e subordinado às relações dos pais (ou equivalentes). O desejo da Casa, num terreno diferente do dos pais significa um desejo de se desprender das relações que os pais constituíram para construir a própria Casa, centralizadas no novo casal e filhos.

A contradição desse processo é que durante a ausência de um ou de ambos os membros ao longo da migração, o próprio núcleo familiar, nas quais as suas relações vinham sendo construídas, resulta incompleto, segundo noções "nativas": um marido ausente significa a ausência da produção cotidiana do parentesco, da cossubstancialidade, das relações. Contra essa incompletude paira o risco constante de esfacelamento e dessubstancialização. Esse risco não é novidade: todos que se envolvem na aventura migratória têm plena consciência desse perigo. Todos sabem que as relações serão colocadas em risco. Isso apenas atesta o valor que a Casa, como um lugar de reconstrução de centralidades nas relações, tem para os sujeitos. Importa se "des-relacionar" das relações dos próprios pais: sair da Casa dos pais, às vezes da casa que pertence aos pais. Esse des-relacionamento é a única possibilidade de assumir um lugar central nas relações que se pretende estabelecer, principalmente 
em relação aos próprios filhos. Basicamente, os aventureiros do projeto migratório familiar querem reproduzir a centralidade de relações que seus pais parecem ter.

Ao emigrar para constituir a própria centralidade do casal na migração, muitos acabam por acentuar a centralidade daquelas relações que pretendem abolir: é o caso dos casais que migram e deixam os filhos sob a guarda de uma das avós. São muitos os exemplos onde a migração é feita em dupla, simultaneamente ou não (em geral o marido migra primeiro e depois leva a mulher). Quando isso acontece, via de regra, quando há filhos, cabe a uma das avós criá-los. Como demonstrou Fonseca (1995), a própria ideia de "criação" é uma fabricação de parentesco por vias não necessariamente consanguíneas. No caso das avós, além dos mecanismos da "criação", ou seja, a convivialidade cotidiana e a comensalidade, os cuidados são ampliados pelos laços consanguíneos. Nesse caso, os filhos do casal ficam mais e mais ligados às relações dos avós, aquelas que os pais pretendem des-relacionar para constituir a própria centralidade. Ou seja, o projeto de construir a Casa pode submeter a própria família a uma acentuação daquelas relações das quais se pretendia afastar.

A vontade do casal que migra junto, em geral, é ampliar a capacidade de juntar recursos e voltar antes, além de preservar a própria relação dos riscos da separação do marido ou da esposa. Nesse projeto, os filhos não entram num primeiro momento. Isso os leva a uma dependência em relação àqueles que vão cuidar dos filhos na ausência do casal. O desfecho dessas situações é um retorno que pode se prorrogar e, nesse caso, os filhos vão "passando" cada vez mais para os avós: ou seja, a cossubstancialidade amplia-se num grau que já se torna quase irreversível. Mesmo quando o casal volta e constrói a Casa, há casos em que os filhos continuam morando com os avós. Ou acontece tudo conforme o planejado, e os pais voltam logo, com os planos realizados e conseguem conquistar a Casa tão almejada. Outra saída também frequente é a constatação que os planos não serão facilmente atingidos ou que, enfim, a vida no exterior pode ser melhor que a vida em Valadares: nesses casos, os planos da Casa são transferidos para o exterior, como novo lugar de construção das relações centralizadas tão importantes às pessoas. Quando isso acontece, a primeira atitude dos casais é buscar os filhos. Há soluções intermediárias e casos variados: famílias que se estruturam permanentemente à distância; casais que levam apenas alguns dos filhos para o exterior, etc. 
As relações podem ser fortalecidas ou enfraquecidas com a ausência prolongada e tudo depende da sua manutenção através de outros meios que não o da convivialidade: a circulação de remessas de dinheiro aparece como um substituto simbólico para essas relações que definiriam uma Casa. A sua manutenção ao longo do tempo significa que os planos originais de constituir a própria Casa estão ainda sendo construídos. A Casa significa, nesse contexto limitado que me dispus a analisar, a produção de relações centradas no casal, significando uma des-relação: ou seja, um rompimento não com os próprios pais, mas com as relações que os pais centralizavam. Com a Casa é possível construir as relações com os filhos como centrais na condução da vida. Assim a Casa, nesse contexto, não seria exatamente a pessoa moral defendida por Lévi-Strauss, mas um índice de autonomia e centralidade de relações. O processo instaurado por essa necessidade resulta numa fragmentação constante dos núcleos familiares, como é óbvio, impedindo uma continuidade como pessoa moral.

Percebemos uma tensão constante, na fala dos entrevistados, entre a ideia de desestruturação da família e os planos e projetos familiares. Os fracassos e as brigas geradas no seio da emigração são contrastados aos casos onde os planos foram bem sucedidos, nos quais a casa foi comprada e a família se reorganizou em novos patamares: ou seja, quando a Casa e a sua sustentação ao longo do tempo garantem uma centralidade nas relações do casal. A tensão entre um modelo familiar "com ausência” permitida e o desejo de um modelo familiar tradicional resulta numa flexibilização das formas de viver a conjugalidade e mudanças radicais na educação e criação dos filhos. Persiste também uma constante ameaça do sonho ruir perante as pressões da situação de migração.

Os riscos na perseguição desse projeto através da emigração ficaram evidentes: o desejo de centralidade de novas relações pode significar o esmaecimento de qualquer relação. Pais podem "sumir” e deixar de enviar dinheiro, encerrando o projeto. Casamentos podem ser rompidos pela fofoca. Filhos podem ser deixados sob riscos de maus tratos, ou podem, ao contrário, inserirem-se definitivamente nas relações de seus avós. O projeto da Casa via emigração põe em risco as relações que pretende centralizar, aquelas entre o casal e o conjunto de filhos, mas continua sendo forte o suficiente para estimular a ação de inúmeras pessoas em Governador Valadares. O processo social de construção de Casas significa um processo infindável de levantamento de 
fronteiras entre núcleos familiares, de fissão e fusão. Esse desejo de construir as próprias fronteiras "nucleares" é um dos motores para a migração internacional, que oferece um atalho para a aquisição do bem fundamental para esse projeto: a casa própria.

\section{Fronteiras e um ponto de vista etnográfico}

Nos últimos anos a questão da fronteira enquanto um tema relevante da pesquisa antropológica tem sido uma referência na análise dos processos migratórios (conferir Donnan e Wilson, 1999; Grimson, 2006; Heyman, 1994, entre outros), seja como uma referência a espaços fronteiriços ou como uma metáfora para processos que ocorrem às margens, nesse sentido uma “antropologia da margem”. Heyman e Cunninghan (2004) separam em duas vertentes os border studies: uma preocupada com sociedades geograficamente fronteiriças e outra que usa a fronteira como metáfora para processos de construção identitária na pós-modernidade, produzida principalmente pelos estudos culturais, mas também por antropólogos interessados na desconexão entre território, Estado e identidade (os estudos de desterritorialização, por assim dizer). Os processos à margem são em geral conotados por uma análise de hibridizações e/ou mestiçagens, como no trabalho de Rosaldo (1989). O caminho é o movimento da análise de processos de interculturalidade (ou mestiçagens, ou hibridizações) em contextos geopolíticos de fronteira para a descoberta desses processos em outros contextos não geopoliticamente fronteiriços, passando, portanto, à análise das margens e fronteiras fluidas das políticas das identidades.

De um deslocamento espacial para o da arena das identidades, temos uma espécie de descoberta entusiasmada da mistura nos processos identitários. O entusiasmo é causado por uma espécie de ingenuidade política muito similar àquela que deu tanto espaço aos estudos culturais: encontra-se uma ferramenta teórica que valoriza a identidade das populações em condições de subalternidade de toda ordem. E, de certa maneira, tenta-se "descentrar" as identidades hegemônicas. Em geral as relações de poder intragrupos ficam em segundo plano. Mesmo as dinâmicas culturais (ou identitárias) desses grupos ficam condicionadas ao lugar de confronto, evitação em relação a identidades (ou culturas) tidas como hegemônicas - sobre as quais, aliás, a prática é a construção essencialista de uma unidade indiferenciada. 
Assim, as identidades subalternas só existem enquanto uma negação (em vários graus) da identidade hegemônica. Em termos antropológicos é, como diria Sahlins (2001) sobre o trabalho de Obeyesekere (1997), uma espécie de antiantropologia, pois destitui os "despossuídos” de tudo que não seja um não-dominante. Há pouco espaço para etnografias que revelem, portanto, a alteridade na prática. Essa é a proposta que pretendo aqui elaborar, ou seja, pensar a construção das fronteiras a partir do grupo que emigra e não em relação preponderante ao Estado e às identidades hegemônicas dos lugares de recepção dos migrantes, no caso de valadarenses em Portugal e de suas famílias em Valadares.

Vários autores chamam, criticamente, a atenção para esse processo de deslumbramento. Em geral o fazem através de etnografias que evidenciam complexidades inesperadas nos processos de hibridização (Ballinger, 2004, por exemplo). Constatam-se, entre outras coisas, as diferenças históricas nesses processos: Heyman e Cunnighan (2004) e Grimson (2006), por exemplo, destacam a necessidade de fazer os border studies voltarem às preocupações socio-históricas e nelas inserir os universos simbólicos, para dar densidade etnográfica à fronteira como metáfora. Ou seja, é realizar os border studies enquanto arenas de estudos etnográficos em locais de fronteira de fato, dando ênfase ao papel dos Estados nacionais nos mecanismos de construção identitária. O remédio para o que se considera exagero da fronteira como metáfora é o estudo histórico-etnográfico nas fronteiras territoriais.

No que se refere ao caso da migração, a tendência tem sido uma preocupação legítima com os processos macroestruturais que constrangem os sujeitos e suas respostas culturais/criativas a essas forças, por um lado, ou, por outro, a análise dos processos de migração como transnacionais, implicando uma outra geografia (física e simbólica) das fronteiras. Assim o grupo migrante de haitianos cria uma "transnação" entre os espaços geográficos nacionais haitianos e americanos, por exemplo (Glick Schiller; Fouron, 1998). Como algo essencialmente "entre”, esses espaços possuem geografias escorregadias, dinâmicas e vivas, relativas às vivências dos transmigrantes. Ambas as perspectivas são essenciais e trouxeram contribuições relevantes para o entendimento de processos migratórios, no presente ou no passado. Mas esse olhar pode ser complementado por uma perspectiva que, se não as contradiz, traz para perto das considerações as práticas e valores desenvolvidos pelos sujeitos migrantes. 
Este artigo procurou lidar com a questão da fronteira levando em conta essas análises críticas e buscando um olhar etnográfico a partir “de dentro" do grupo estudado (Viveiros de Castro, 1999). Entretanto, acredito que um olhar crítico sobre as fronteiras seja encontrado não somente nas etnografias transfronteiriças, mas também em situações fronteiriças. No caso, tratei de verificar onde estão as fronteiras para os emigrantes brasileiros e seus familiares, na cidade de Governador Valadares. Demonstrei que há uma sucessão de fronteiras vivenciadas pelos sujeitos e tentei aqui dar conta de duas delas: primeiramente o papel das fronteiras geopolíticas na decisão e custo de migrar e suas diversas implicações e, por fim, a questão que impulsiona a necessidade da migração, que é a fronteira entre famílias, o difícil processo de construir limites que definem novos núcleos familiares, também com suas diversas implicações.

Entre as duas fronteiras analisadas, percebe-se imediatamente uma conexão: as "fronteiras internas", por assim dizer, produzem a necessidade de cruzar as fronteiras geopolíticas e conduzem à diversificação dos destinos, quando o destino principal, os EUA, se torna cada vez mais inacessível. O jogo constante de produção de núcleos familiares independentes é entrecortado pela migração, que aparece como um atalho eficiente para a concretização desse sonho. Esse atalho é constrangido pelas fronteiras geopolíticas, determinando a intensidade da movimentação e, em certa medida, a direção do fluxo. Mas o atalho é uma necessidade para a construção de novas fronteiras familiares, ou seja, da constituição de núcleos familiares autônomos e potencialmente centralizadores de relações. São essas as fronteiras, portanto, que se conectam complexamente à movimentação. Construir "fronteiras internas" aos grupos familiares tem relações significativas com o cruzamento de fronteiras geopolíticas e com a constituição de fluxos constantes de migrações.

Assim, a própria relação com a movimentação é permeada por universos simbólico-culturais próprios à população migrante. É preciso uma etnografia que reflita sobre a inter-relação da migração com esses valores compartilhados, como é o projeto da Casa própria em Valadares. Esse processo cultural é relevante na análise das movimentações valadarenses, e na escolha dos destinos, pois permite entender como a mobilidade não é interrompida pelas políticas americanas de restrição à migração (e também mexicanas), mas apenas reconduzida a outro lugar que possibilite, ainda que menos eficientemente, a continuidade do jogo arriscado da migração. Assim, espero ter demonstrado o que significa uma contribuição a partir "de dentro" do grupo estudado: a 
intenção é entender o fenômeno da migração e circulação através de fronteiras a partir dos valores e símbolos correntes entre os emigrantes, no caso os valadarenses. Aqui chegamos à conclusão que as "fronteiras externas" são cruzadas num processo conectado à criação de novas "fronteiras internas”.

\section{Referências}

ALMEIDA, A. G. de. A formação da identidade do imigrante valadarense em Portugal. Relatório final de Iniciação Científica (ProPG-UFSCar). Universidade Federal de São Carlos, São Carlos, 2006.

ALMEIDA, A. G. de. Valadarenses em Portugal: novas identidades e mercado de trabalho. Relatório final de Iniciação Científica (Fapesp). Universidade Federal de São Carlos, São Carlos, 2007.

ASSIS, G. O. Estar aqui..., estar lá...: uma cartografia da emigração valadarense para os EUA. In: SALES, T.; REIS, R. R. (Org.). Cenas de um Brasil migrante. São Paulo: Boitempo, 1999. p. 125-166.

BALLINGER, P. "Authentic hybrids" in the Balkan borderlands. Current Anthropology, v. 45, n. 1, p. 31-60, February 2004.

CARSTEN, J. The substance of kinship and the heat of the hearth: feeding, personhood and relatedness among Malays in Pulau Langkawi. American Ethnologist, v. 22, p. 223-241, 2004.

DONNAN, H.; WILSON, T. Borders: frontiers of identity, nation and state. Oxford: Berg, 1999.

DURHAM, E. A caminho da cidade. São Paulo: Perspectiva, 1978.

FELDMAN-BIANCO, B. A saudade portuguesa na América: artefatos visuais, histórias orais e a tradução de culturas. Revista Crítica de Ciências Sociais, Coimbra, v. 45, p. 113-126, 1996.

FONSECA, C. Caminhos da adoção. São Paulo: Cortez, 1995.

FONSECA, C. Apresentação: de família, reprodução e parentesco: algumas considerações, Cadernos Pagu, n. 29, p. 9-35, jul./dez. 2007. 
FUSCO, W. Redes sociais nas migrações entre Governador Valadares e os Estados Unidos. In: MIGRAÇÕES internacionais: contribuições para política. Brasília: CNPD, 2001. p. 427-446.

GLICK SCHILLER, N.; FOURON, G. Transnational lives and national identities: the identity politics of haitian immigrants. In: SMITH, M.; GUARNIZO, L. Transnationalism from below. New Brunswick, N.J.: Transaction Publishers, 1998. p. 130-161. (Special issue of Comparative Urban and Community Research, v. 6).

GRIMSON, A. Cultures are more hybrid than identifications: a dialogue on borders from the southern cone. Latino Studies, v. 4, p. 96-119, 2006.

GUERREIRO, A. Os filhos da migração transnacional: novas estruturas familiares e a educação das crianças na região de governador Valadares. Relatório final de Iniciação Científica (CNPq-PIBIC). Universidade Federal de São Carlos, São Carlos, 2008.

HEYMAN, J. The mexican-United States border in anthropology: a critique and reformulation. Journal of Political Ecology, v. 1, n. 1, p. 43-65, 1994.

HEYMAN, J.; CUNNINGHAM, H. Introduction: mobilities and enclosures at borders. Identities: Global Studies in Culture and Power, v. 11, p. 289-302, 2004.

LÉVI-STRAUSS, C. Minhas palavras. São Paulo: Brasiliense, 1986.

LÉVI-STRAUSS, C. História e etnologia. Campinas: Unicamp, 1999. (Textos Didáticos n. 24).

MACHADO, I. J. R. Implicações da imigração estimulada por redes ilegais de aliciamento: o caso dos brasileiros em Portugal. Iha: Revista de Antropologia, v. 7, n. 1-2, p. 187-212, 2005.

MACHADO, I. J. R. Laços de sangue e fluxo de dinheiro: notas sobre o parente ausente no contexto migratório transnacional Portugal/Governador Valadares. In: REUNIÃO BRASILEIRA DE ANTROPOLOGIA, 25., 2006, Goiânia. Anais... Goiânia, 2006. p. 1-27. 1 CD-ROM. 
MACHADO, I. J. R.; REIS, E. S. Algumas conclusões a cerca do fluxo de valadarenses para Portugal. Teoria \& Pesquisa,v. 16, n. 1, p. 153-166, 2007.

MATOS VIEGAS, S. Terra calada: os tupinambás na mata atlântica do sul da Bahia. Rio de Janeiro: 7 letras, 2007.

OBEYESEKERE, G. The apotheosis of Captain Cook: European mythimaking in the Pacific. Princeton: Princeton University Press, 1997.

PINA-CABRAL, J. de. Os contextos da antropologia. Lisboa: Difel, 1991.

PEIXOTO, J.; FIGUEIREDO, A. Imigrantes brasileiros e mercado de trabalho em Portugal. In: MACHADO, I. J.R. (Org.). Um mar de identidades: imigração brasileira em Portugal. São Carlos: Edufscar, 2006. p. 43-80.

REIS, E. R. Questões sobre a indústria da emigração: conexões Portugal/ Governador Valadares. Relatório final de Iniciação Científica (CNPq-PIBIC). Universidade Federal de São Carlos, São Carlos, 2006.

REIS, E. R. Casamento e família em contexto migratório. Relatório final de Iniciação Científica (CNPq-PIBIC). Universidade Federal de São Carlos, São Carlos, 2007.

ROSALDO, R. Culture and truth. Boston: Beacon Press, 1989.

SAHLINS, M. Como pensam os nativos: sobre o Capitão Cook, por exemplo. São Paulo: Edusp, 2001.

SALES, T. Brasileiros longe de casa. São Paulo: Cortez, 1999.

SCHNEIDER, D. American kinship: a cultural account. New Jersey: PrenticeHall, 1968.

SIQUEIRA, S. Emigrantes da microrregião de Governador Valadares nos EUA: projeto de retorno e investimento. In: ENCONTRO NACIONAL DE ESTUDOS POPULACIONAIS, 15., 2006, Caxambu. Anais... Campinas: Abep, 2006. v. 1, p. 1-35.

SIQUEIRA, S. O sonho frustrado e o sonho realizado: as duas faces da migração para os EUA. Nuevo Mundo-Mundos Nuevos, v. 7, p. 21, 2007. 
SOARES, W. Emigração e (i)mobilidade residencial: momentos de ruptura na reprodução/continuidade da segregação social no espaço urbano. In: SALES, T.; REIS, R. R. (Org.). Cenas de um Brasil migrante. São Paulo: Boitempo, 1999. p. 167-192.

STABELINI, F. Parentesco, totemismo e sistemas de classificação no contexto migratório de Governador Valadares. Relatório final de Iniciação Científica (CNPq-PIBIC). Universidade Federal de São Carlos, São Carlos, 2008.

VIVEIROS DE CASTRO, E. Etnologia brasileira. In: MICELI, S. (Org.). $O$ que ler na ciência social brasileira (1970-1995). São Paulo: Sumaré; Brasília: Anpocs, 1999. p. 109-224.

Recebido em: 29/09/2008 Aprovado em: 19/01/2009 